\title{
Oocyte-sperm interactions in the fertilization of birds
}

\author{
ALEKSANDRA KRAWCZYK, JADWIGA JAWORSKA-ADAMU
}

\begin{abstract}
Department of Animal Anatomy and Histology, Faculty of Veterinary Medicine, University of Life Sciences in Lublin,
\end{abstract} Akademicka 12, 20-033 Lublin, Poland

\section{Krawczyk A., Jaworska-Adamu J. Oocyte-sperm interactions in the fertilization of birds}

Summary

A thorough understanding of the mechanisms leading to the interaction between the sperm and the ovum in the process of fertilization in birds can facilitate more effective programming and control of the reproduction of these animals in breeding farms. In addition, it may allow the introduction of extracorporeal fertilization techniques, which may be important in the creation of transgenic animals and the reproduction of endangered species. In birds, the process of fertilization is not well known. It is conditioned by a series of interactions between mature reproductive cells. Oocytes are formed in the ovarian follicles of the left ovary. After ovulation, an ovum in the metaphase of the second meiotic division enters the oviduct along with the inner perivitelline layer (IPVL). It gets fertilized in this infundibulum. Male gametes are formed in paired testes located in the abdominal cavity. Sperm cells in the female reproductive tract do not require capacitation and are already fully capable of fertilization. As a result of internal insemination, male reproductive cells enter the oviduct. In this organ, they are selected and stored in the primary and secondary sperm storage tubules of the mucous membrane. They are released in batches shortly before ovulation. After reaching the oocyte, the sperm binds to the IPVL. This induces an acrosomal reaction that allows the male reproductive cells to penetrate to the surface of the oocyte, especially at the germinal pole. Next, as a result of physiological polyspermy, many sperm cells reach the ooplasm where they form haploid male pronucleus. This phenomenon is necessary to activate an polylecithal egg and produce a haploid female pronucleus. In the final stage, the female pronucleus merges with the single male pronucleus, which leads to the formation of a diploid zygote. The excess male pronuclei present in ooplasm are broken down by endonucleases (DNases). Understanding the mechanisms leading to the interaction between sperm and oocyte in birds may allow for more accurate programming and breeding of these animals in poultry farms and the introduction of extracorporeal fertilization techniques. In addition, it could be useful for the reproduction of endangered bird species

Keywords: fertilization, bird, physiological polyspermy

The course of the fertilization process and the molecular mechanisms that guide it in birds is not fully understood. In the natural environment, birds only reproduce under favorable conditions. In breeding, the reproduction of these animals is programmed and controlled. Proper breeding of birds is important because it affects the production, health, and profitability of the flock. The key element of the reproduction process is the fertilization. This phenomenon consists of the combination of cytoplasm (plasmogamy) and cell nuclei (karyogamy) of mature male and female reproductive cells. It initiates the creation of a new organism (5, 13). Precise determination of the mechanisms leading to fertilization in birds is important in the programming and control of breeding in farms, but also in the creation of transgenic animals and the reproduction of species threatened with extinction.

\section{The encounter of mature male and female reproductive cells in birds}

The precondition for the fertilization to take place is the encounter of mature reproductive cells. The gametes attain their maturity partly during development. In male birds, sperm is produced in paired testes located in the abdominal cavity (Fig. 1A). Then they are shifted to the paired epididymis and the long deferent ducts. Their endings expand to form seminal vesicles in which sperm is stored. In the deferent duct, male gametes gain full ability to move and fertilize (Fig. 1B). Males of most species of birds do not have a phallus. Its functions are carried out by folds and bulges of the bottom wall of the cloaca. In addition, birds do not have male accessory glands. The plasma of the semen is the secretion produced in the testes, epididymis and deferent ducts $(2,7,19,28)$. 


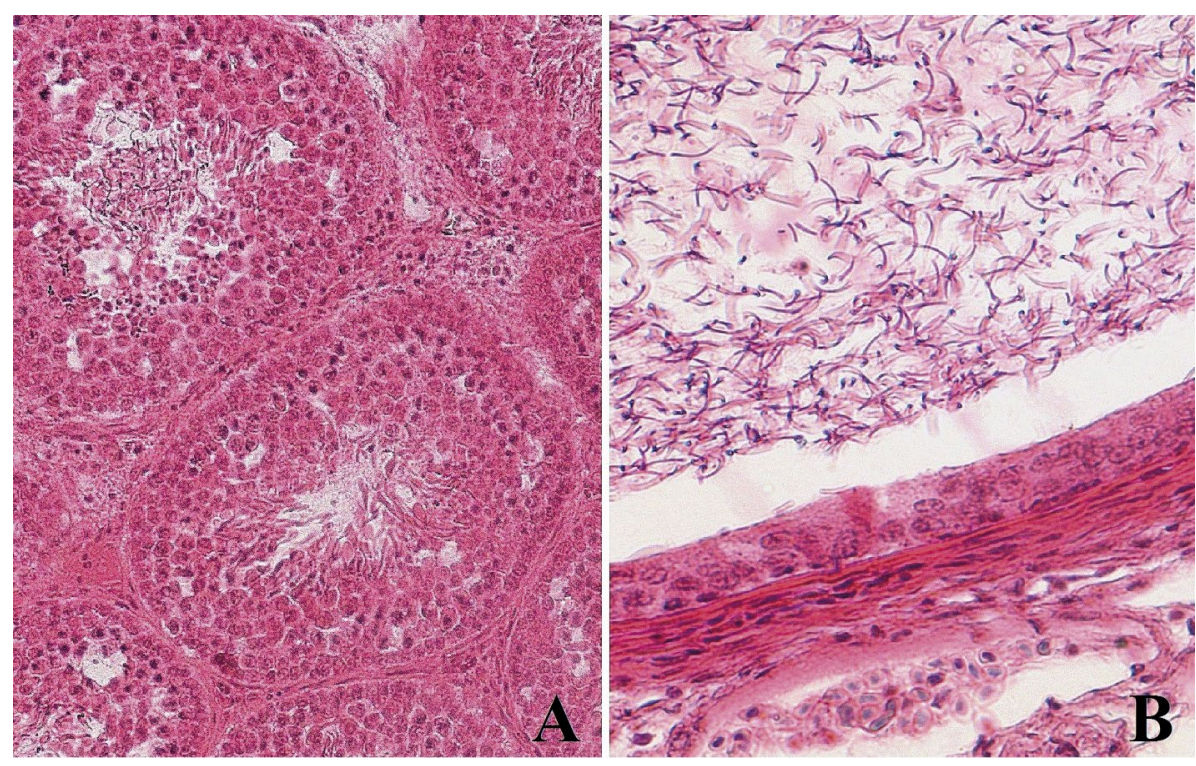

Fig. 1. Testis (A) and deferent duct (B) of a cock $(\mathrm{H}+\mathrm{E})$; magnified approx. $200 \times$
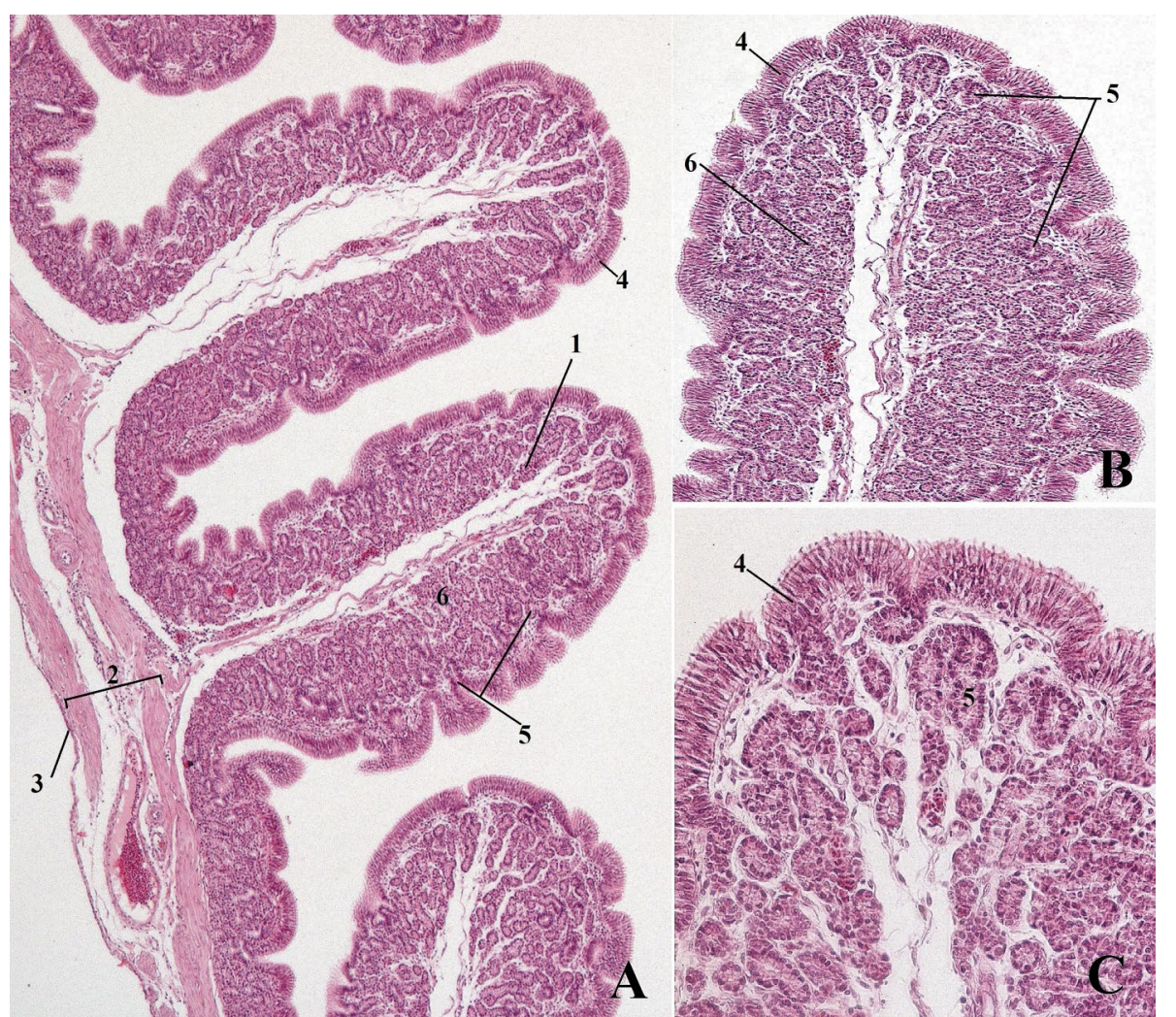

Fig. 2. Hen's oviduct $(H+E)$ : $A$ - magnified approx. $100 \times, B-$ magnified approx. $200 \times, C$ - magnified approx. $400 \times$

Explanations: 1 - mucous membrane; 2 - muscular membrane; 3 - serous membrane; 4 - epithelium; 5 -glands; 6 - subepithelial tissue

In females of most species of birds, gametes usually develop in the ovarian follicles of the left ovary. Oocytes are polylecithal, and yellow yolk accumulates in the form of a large ball on the vegetal pole. The animal pole concentrates the cytoplasm with the cell nucleus in the form of a germinal disc $(5,15)$. The oolema surrounding the yolk is discontinuous and produces single microvilli. Above the germinal disc, the cell membrane is continuous and forms numerous, branched microvilli directed towards the perivitelline space. This space can be seen between the oolema and the inner perivitelline layer (IPVL), which is formed in the ovary around the oocyte as the primary egg shield (Fig. 3) $(3,5,17,18,28)$. Under the influence of hormones the mature ovarian follicle raptures and releases the secondary oocyte in a metaphase of the second meiotic division (ovulation). The ovum, surrounded by the IPVL, enters the infundibulum of the left oviduct. Its here fertilization occurs. Afterward, the fertilized oocyte goes through the following sections of the oviduct, i.e. magnum, isthmus, uterus, and vagina joining the cloaca (Fig. 2) (2, 5). During migration, the ovum is surrounded by secondary egg shields. Their task is to protect the embryo and allow it to grow outside the mother's body at the expense of material collected in the form of yolk $(5,7,15)$.

\section{The migration of sperm in the female reproductive tracts of birds}

In birds, the encounter of mature male and female gametes is made possible through internal insemination. Sperm cells are introduced into the female's cloaca during copulation. This process is not synchronized with ovulation (2). Male gametes reach the vaginal part of the oviduct near the uterus. This place is described as the utero-vaginal junction (UVJ). This section of the oviduct is approximately $2-3 \mathrm{~cm}$ long $(20,28)$. The epithelium of mucosa of UVJ forms crypts with a length of approx. $200 \mu \mathrm{m}$ called primary sperm storage tubules (SSTs) $(2,20,28)$. Immediately after copulation, sperm cells gather in large numbers in SSTs creating the so-called seminal nests $(5,6)$. There is a suitable microenvironment inside the tubules, thanks to which the male gametes retain their lifespan from 2-3 weeks (rooster) to 15 weeks, e.g. turkey $(2,6,20)$. Sperm cells from seminal nests are released in batches before each ovulation $(9,20)$. Even before the ovarian follicle ruptures, motile reproductive cells migrate to the infundibulum, where they penetrate into the invaginations of the mucosal eptthelium, the so-called secondary SSTs. These structures are short and accumulate only a few sperm cells (28). 


\section{Sperm penetration of the IPVL of avian oocyte}

During fertilization in birds, a multistep interaction of the sperm with the oocyte takes place. In the first phase, male gametes penetrate through the IPVL. This process precedes sperm binding and the induction of an acrosomal reaction in it. The IPVL is fibrous. The fibers are made of glycoproteins, mainly ZP1 and ZP3. In addition, ZP2, ZP4 and ZPD are present in small amounts $(11,14,17,18)$. The ZP1 and ZP3 glycoproteins are interconnected and in this form they get incorporated evenly into the IPVL around the ovum $(17,18)$. These compounds function as receptors and binding sites for sperm $(4,10,28)$. However, ZP2 gets located only in the area of the germinal disc and can act as a factor attracting male gametes close to the germinal disc of oocyte $(11,16)$. The binding of sperm cells initiates a cascade of reactions in them leading to the release of enzymes from the acrosome and the unveiling of the inner acrosomal membrane. In birds, this process does not require sperm capacitation (21, 28 ). The N-glycans of the IPVL glycoproteins, mainly $\mathrm{ZP} 1$, induce an acrosomal reaction $(7,11,14,28)$. The release of proteolytic enzymes from the acrosome and the unveiling of the inner acrosomal membrane most likely occurs after the top part of the head is detached as a result of membrane fusion in the rear region of the acrosome (1). The acrosomal reaction allows sperm penetration through the IPVL. Male gametes pave the way by engaging the participation of a multi-enzymatic protease complex. These enzymes break down ZP1 into single amino acids and peptides and lead to the release of ZP3 (11). The sperm hydrolyse a hole of approx. $9 \mu \mathrm{m}$ diameter and within about 3 minutes it passes through the IPVL $(25,28)$. Sperm cells have a limited time of interaction with the IPVL. Within 15-30 min. after ovulation an outer perivitelline layer (OPVL) around the oocytes is formed $(8,25,27,28)$. The OPVL acts as a mechanical barrier for sperm and the enzymes contained therein inhibit the induction of the acrosomal reaction (Fig. 3) $(23,25,27)$.

\section{Penetration of multiple sperm cells into the ooplasm of avian ovum}

Male gametes, passing through the IPVL at the germinal pole, enter the perivitelline space. In birds, the phenomenon of physiological polyspermy is observed. Multiple sperm cells interact with the oolema covered with numerous microvilli and penetrate into the ooplasm $(9,12,24,28)$. Sperm penetration occurs through the fusion of the inner acrosomal membrane with the oolema and by phagocytosis. Whole male gametes are absorbed into the ooplasm, which leads to plasmogamy (Fig. 3) $(13,28)$. Polyspermia facilitates fertilization of polylecithal ovum, due to the short duration of the interaction of male gametes with the IPVL

(9). Only one of these gametes participates in karyogam $y$. The remaining numerous male gametes are necessary for the activation of the oocyte. Their presence contributes to the increase in the level of calcium ions in the ooplasm. This triggers enzymatic reactions that allow the completion of the second meiotic division by the secondary oocyte $(5,9)$. In addition, sperm contains C zeta phospholipase, aconitase, cytidine synthetase, which are
Fig. 3. Oocyte interactions with sperm in birds: 1 - the surface of the oocyte surrounded by IPVL, 2 sperm binding to IPVL, 3 - acrosomal reaction and sperm penetration of IPVL, 4 - sperm interaction with the oolema, 5 - penetration of sperm cell into the ooplasm

Explanations: IPVL - inner perivitelline layer; OPVL - outer perivitelline layer 
also included in the activation factors $(7,9,11)$. In chickens and turkeys, at least 6 sperm cells have been shown to be necessary for the proper course of the fertilization process $(26,28)$.

\section{Formation of pronuclei and karyogamy in birds}

The sperm cell nuclei present in ooplasm undergo numerous structural changes leading to the formation of haploid male pronuclei. A haploid ootide develops as a result of oocyte activation after the sperm transformation. Also a nuclear envelope is formed around the famel nuclear material, resulting in the formation of the haploid female pronucleus at the center of germinal disc $(5,28)$. Male and female pronuclei combine in the process of karyogamy to form the zygote diploid nucleus. At the same time, a spindle is formed from the centriole brought by the sperm, which initiates numerous mitotic divisions of the germinal disc and the creation of a new complex organism $(22,28)$. One male pronucleus, which most probably arises from the sperm bound to the oolema located directly above the nucleus of the oocyte, is involved in karyogamy. The genetic material of the extra spermatozoa is degraded by DNases I and II present in the ooplasm at the early stage of embryonic development. This phenomenon inhibits pathological polyspermia $(15,23,24,28)$. Avian sperm cells are homogametic (ZZ), while the ova are heterogametic (ZW). The male gamete carries $Z$-heterochromosome, whereas the ootide carries the $\mathrm{Z}$ or $\mathrm{W}$ heterochromosome. The presence of $\mathrm{ZZ}$ chromosomes leads to the development of paired male gonads-testes, while ZW leads to fully developed left ovary and oviduct (5).

\section{References}

1. Ahammad M. U., Nishino C., Tatemoto H., Okura N., Okamoto S., Kawamoto Y., Nakada T:: Acrosome reaction of fowl sperm: Evidence for shedding of the acrosomal cap in intact form to release acrosomal enzyme. Poult. Sci. 2013, 92, 798-803.

2. Bakst M. R., Dymond J. S.: Artificial insemination in poultry. Success in Artificial Insemination, [in:] Lemma A. (ed.): Quality of Semen and Diagnostics Employed. InTech Publisher, Rijeka 2013, p. 175-195.

3. Bakst M. R., Eastridge J., Malecki I. A.: The inner perivitelline layer sperm hole assay: Use of filter paper rings for the isolation of the perivitelline layer overlying the germinal disc and new observations on its morphology. J. Appl. Poult. Res. 2014, 23, 121-128.

4. Bausek N., Ruckenbauer H. H., Pfeifer S., Schneider W. J., Wohlrab F.: Interaction of sperm with purified native chicken ZP1 and ZPC proteins. Biology Reproduction 2004, 71, 684-690.

5. Bielańska-Osuchowska Z.: Embriologia. PWRiL, Warszawa 2001.

6. Birkhead T. R., Moller A. P.: Numbers and size of sperm storage tubules and the duration of sperm storage in birds: A comparative study. Biol. J. Linn. Soc. 1992a, 45, 363-372.

7. Blesbois E.: Biological Features of the Avian Male Gamete and their Application to Biotechnology of Conservation. J. Poult. Sci. 2012, 49, 141-149.

8. Calkins J. D., El-Hinn D., Swanson W. J.: Adaptive Evolution in an Avian Reproductive Protein: ZP3. J. Mol. Evol. 2007, 65, 555-563.

9. Hemmings N., Birkhead T. R.: Polyspermy in birds: sperm numbers and embryo survival. Proc. R. Soc. B 2015, 282, 20151682.

10. Horrocks A. J., Stewart S., Jackson L., Wishart G. J.: Induction of acrosomal exocytosis in chicken spermatozoa by inner perivitelline-derived $\mathrm{N}$-linked glycans. Biochem. Biophys. Res. Commun. 2000, 278, 84-89.

11. Ichikawa Y., Matsuzaki M., Hiyama G., Mizushima S., Sasanami T.: Sperm-egg interaction during fertilization in birds. J. Polut. Sci. 2016, 53, 173-180.
12. Iwao Y: Egg activation in physiological polyspermy. Reproduction 2012, 144, $11-22$.

13. Jura C., Klag J.: Podstawy embriologii zwierząt i człowieka. PWN, Warszawa 2005.

14. Kinoshita M., Rodler D., Sugiura K., Matsushima K., Kansaku N., Tahara K., Tsukada A., Ono H., Yoshimura T., Yoshizaki N., Tanaka R., Kohsaka T. Sasanami T: Zona pellucida protein ZP2 is expressed in the oocyte of Japanese quail (Coturnix japonica). Reproduction 2010, 139, 359-371.

15. Maleszewski M.: Ćwiczenia z biologii rozwoju zwierząt. Wydawnictwo UW Warszawa 2005.

16. Nishio S., Kohno Y., Iwata Y., Arai M., Okumura H., Oshima K., Nadano D., Matsuda T:: Glycosylated Chicken ZP2 Accumulates in the Egg Coat of Immature Oocytes and Remains Localized to the Germinal Disc Region of Mature Eggs. Biol. Reprod. 2014, 91, 107, 1-10.

17. Rodler D.: Histochemical Detection of Glycoconjugates in the Inner Perivitelline Layer of Japanese Quail (Coturnix japonica). Anat. Histol. Embryol. 2011, 40, 441-449.

18. Rodler D., Sasanami T., Sinowatz F.: Assembly of the inner perivitelline layer, a homolog of the mammalian zona pellucida: an immunohistochemical and ultrastructural study. Cells Tissues Organs 2012, 195, 330-339.

19. Sasanami T., Izumi S., Sakurai N., Hirata T., Mizushima S., Matsuzaki M., Hiyama G., Yorinaga E., Yoshimura T., Ukena K., Tsutsui K.: A unique mechanism of successful fertilization in a domestic bird. Sci. Rep. 2015, 5, 7700.

20. Sasanami T., Matsuzaki M., Mizushima S., Hiyama G.: Sperm Storage in the Female Reproductive Tract in Birds. J. Reprod. Dev. 2013, 59, 334-338.

21. Sasanami T., Yoshizaki N., Dohra H., Kubo H.: Sperm acrosin is reponsible for the sperm binding to the egg envelope during fertilization in Japanese quail (Coturnix japonica). Reproduction 2011, 142, 267-276.

22. Snook R. R., Hosken D. J., Karr T. L.: The biology and evolution of polyspermy: insights from cellular and functional studies of sperm and centrosomal behavior in the fertilized egg. Reproduction 2011, 142, 779-792.

23. Stępińska U., Olszańska B.: Detection of deoxyribonuclease I and II activities in Japanese quail oocytes. Zygote 2001, 9, 1-7.

24. Stępińska U., Olszańska B.: DNase I and II present in avian oocytes: a possible involvement in sperm degradation at polyspermic fertilisation. Zygote 2003, $11,35-42$

25. Wishart G. J.: Avian sperm: egg interaction: mechanisms and practical application for analysis of fertility. Avian Poult. Biol. Rev. 2002, 13, 215-222.

26. Wishart G. J.: Quantitive aspects of sperm:egg interaction in chickens and turkey. Anim. Reprod. Sci. 1997, 48, 81-92.

27. Wishart G. J., Fairweather J. O.: The chicken „Fertilization Window”. Avian Poult. Biol. Rev. 1999, 9, 124.

28. Wishart G. J., Horrocks A. J.: Fertilization in Birds, [in:] Tarin J. J., Cano A. (ed.): Fertilization in Protozoa and Metazoan Animals: Cellular and Molecular Aspects. Springer, Berlin 2000, p. 193-222.

Corresponding author: Prof. dr hab. Jadwiga Jaworska-Adamu, ul. Akademicka 12, 20-033 Lublin, Poland; e-mail: jadwiga.jaworska@up.lublin.pl 